\section{Identities of and Phenotypic Variation for Epicuticular Waxes among Leaves and Plants from Inbred Onion Populations}

\author{
Jiffinvir Khosa and Derek Hunsaker \\ Department of Horticulture, 1575 Linden Drive, University of Wisconsin, \\ Madison, WI 53706
}

\section{Michael J. Havey}

U.S. Department of Agriculture-Agricultural Research Service and Department of Horticulture, 1575 Linden Drive, University of Wisconsin, Madison, WI 53706

Additional index words. gas chromatography, insect resistance, leaf waxes, mass spectrometry, onion thrips

\begin{abstract}
The amounts and types of epicuticular waxes on onion (Allium cepa) leaves affect feeding damage by onion thrips (Thrips tabaci). This study used gas chromatography mass spectrometry (GCMS) to establish the identities of waxes and measure over time wax amounts on leaves of inbred onion plants with glossy, semiglossy, and waxy foliage. Nine waxes were detected on leaves of all inbreds, and higher coefficients of variation (Cv) were observed for less abundant waxes on foliage of doubled haploid onions. Older leaves had higher amounts of waxes compared with younger leaves on the same plant. Except for one minor wax, amounts of individual waxes on leaves were not significantly different for plants of different ages. There was a significant inbred by sampling date interaction due to lower amounts of waxes on the leaves of older plants from the semiglossy inbred. These results indicate that there is little advantage to multiple samplings of leaves over time from the same plant and resources may be better used to evaluate more plants. The relatively large cvs for amounts of specific waxes may reduce response to selection for unique epicuticular wax profiles to develop onion populations that suffer less feeding damage by onion thrips.
\end{abstract}

Onion foliage shows phenotypic variation for types and amounts of epicuticular waxes (Damon et al., 2014). The wild-type onion accumulates higher amounts of total wax, and its visual phenotype is referred to as "waxy." Phenotypes with lower amounts of total and/ or individual waxes have leaves with lightergreen color (Damon et al., 2014; Molenaar, 1984). These onions can be visually classified

Received for publication 3 Sept. 2020. Accepted for publication 9 Oct. 2020.

Published online 9 November 2020.

We gratefully acknowledge the support of the U.S. Department of Agriculture (USDA)-National Institute of Food and Agriculture grants 20166013-24590 from the Organic Research and ExtenSpecialty Crops Research Initiative and the technical assistance of Christy Stewart. data; however, the USDA neither guarantees nor warrants the standard of the product, and the use of the name by USDA implies no approval of the product to the exclusion of others that may also be suitable.

M.J.H. is the corresponding author. E-mail: michael. havey@usda.gov.

This is an open access article distributed under the CC BY-NC-ND license (https://creativecommons. org/licenses/by-nc-nd/4.0/). sion Initiative and 2018-51181-28435 from the

Names are necessary to report factually on available phenotypic variation for amounts of epicuticular waxes on leaves and plants of different ages from inbred lines of onion. Our overall objective was to assess variation for amounts of individual waxes on onion foliage toward selection of unique wax profiles to reduce feeding damage by onion thrips.

\section{Materials and Methods} and B5351 with semiglossy foliage were from the USDA onion-breeding program (Damon et al., 2014), and waxy doubled haploids (DH) 2107 and 066619 were described by Hyde et al. (2012). Plants were grown in a soil mix (Promix, Sun-Gro Horticulture, Agawam, MA) from October to January in a greenhouse at the University of Wisconsin (UW)-Madison, with supplemental lighting by high-pressure sodium lamps for $14 \mathrm{~h}$ at $25{ }^{\circ} \mathrm{C}$ days and $20{ }^{\circ} \mathrm{C}$ nights. Plants were randomly arranged in the greenhouse, watered daily, and fertilized once per week with $0.5 \times$ Hoagland's solution (Hoagland and Arnon, 1950). Five plants of each inbred line were randomly chosen at 60,90 , and $120 \mathrm{~d}$ after planting, and the youngest fully expanded leaf on each plant was identified, followed by the next two older leaves, and labeled as youngest, middle, and oldest leaves. Two adjacent pieces of $\approx 50 \mathrm{~mm}$ were taken from each of three leaves from each plant, and plants were discarded after sampling. Extraction of waxes from leaf pieces was previously described by Damon et al. (2014). After extractions, leaf pieces were dried in an oven at $80^{\circ} \mathrm{C}$ for about $5 \mathrm{~d}$ and dry weights were measured. Twenty-five $\mu \mathrm{L}$ of docosane (Sigma-Aldrich, St. Louis, MO) dissolved in HPLC-grade chloroform (stock concentration of $1 \mathrm{mg} \cdot \mathrm{mL}^{-1}$ ) were added to each extraction. Samples were prepared and run on the gas chromatography mass spectrometry (GCMS) and peak areas quantified as previously reported (Damon et al., 2014). To confirm the identities of relatively minor waxes on onion foliage, chemical standards for the waxes heptacosane, 1-hexacosanol, nonacosane, and hentriacontane (all from Sigma-Aldrich) were
Onion inbreds B9885 with glossy foliage

Table 1. Probabilities $(P)$ of significance levels from analyses of variance for amounts of epicuticular waxes on three adjacent leaves (Lf) sampled (S) three times from four inbred lines (L) of onion. The split-plot analysis considered $\mathrm{S}$ as the main plot and $\mathrm{L}$ and $\mathrm{Lf}$ as subplots.

\begin{tabular}{|c|c|c|c|c|c|c|c|c|c|c|c|}
\hline \multirow[b]{2}{*}{$\mathrm{SV}^{\mathrm{z}}$} & \multirow[b]{2}{*}{$\mathrm{df}^{\mathrm{z}}$} & \multicolumn{10}{|c|}{$P$ levels ${ }^{\mathrm{y}}$ for amount of } \\
\hline & & Heptol $^{\mathrm{x}}$ & $\operatorname{Hex}^{x}$ & $\operatorname{Oct}^{\mathrm{x}}$ & $\operatorname{Tri}^{\mathrm{x}}$ & $\operatorname{Octd}^{\mathrm{x}}$ & $\operatorname{Hept}^{\mathrm{x}}$ & $\operatorname{Non}^{\mathrm{x}}$ & Hent $^{x}$ & $\mathrm{H} 16^{\mathrm{x}}$ & Total $^{x}$ \\
\hline Sample (S) & 2 & & & & & & & & * & & \\
\hline Line $(\mathrm{L})$ & 3 & & $* * *$ & $* *$ & $*$ & & & & $* *$ & $* * *$ & $* * *$ \\
\hline Error $\left(\mathrm{S}^{*} \mathrm{~L}\right)$ & 6 & & & & & & & & & & \\
\hline Leaf (Lf) & 2 & & $* *$ & $* * *$ & $* * *$ & & $* * *$ & $* * *$ & $* *$ & $* *$ & $* * *$ \\
\hline $\mathrm{L} \times \mathrm{Lf}$ & 6 & & $* *$ & $* *$ & $*$ & & & & & $* *$ & $* * *$ \\
\hline Error & 16 & & & & & & & & & & \\
\hline
\end{tabular}

${ }^{\mathrm{z}} \mathrm{SV}=$ source of variation; $\mathrm{df}=$ degrees of freedom

${ }^{\mathrm{y}}$ Significance levels are $* * * P<0.001, * * P<0.01$, or $* P<0.05$. Blank positions indicate nonsignificance $(P>0.05)$.

${ }^{\mathrm{x}}$ Waxes are heptadecanol-1 (Heptol), hexacosanol-1 (Hex), octacosanol-1 (Oct1), triacontanol-1 (Tri), 1 ethenyloxy octadecane (Octd), heptacosane (Hept), nonacosane (Non), hentriacontane (Hent), and hentriacontanone-16 (H16). Total = sum of peak areas from all waxes. 
A)

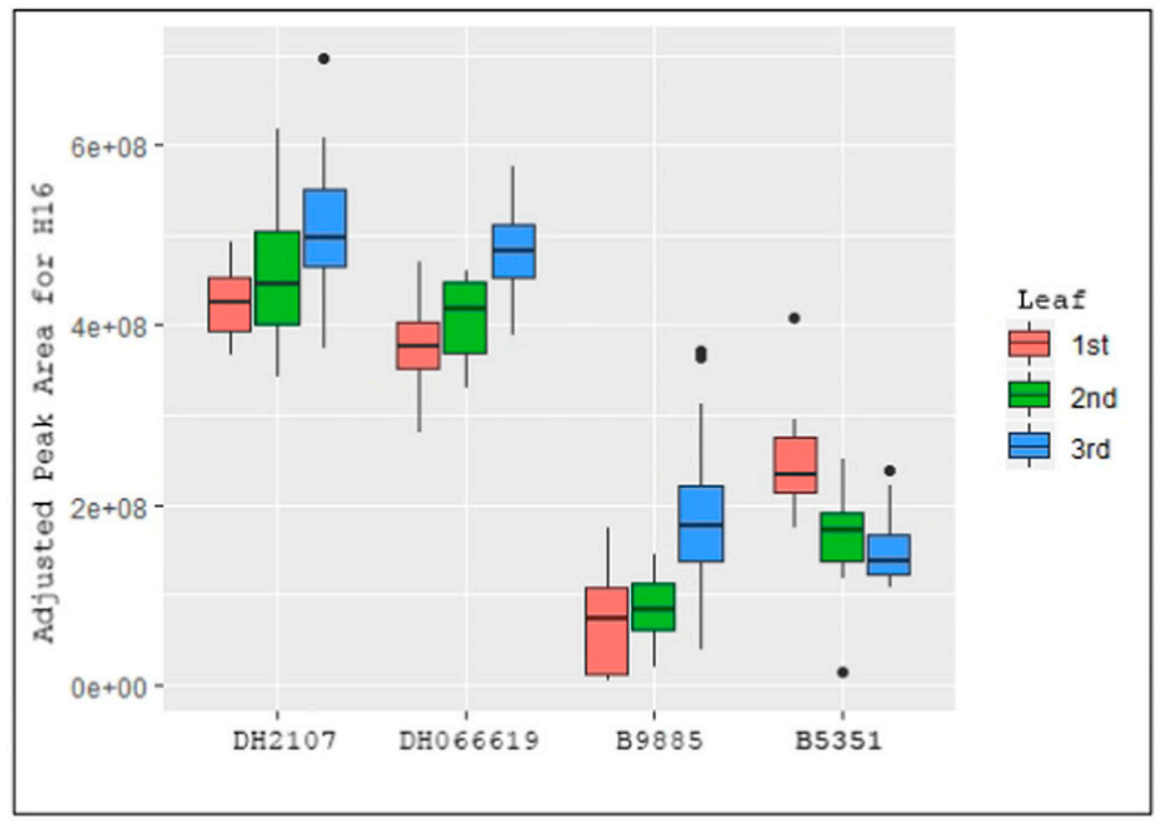

B)

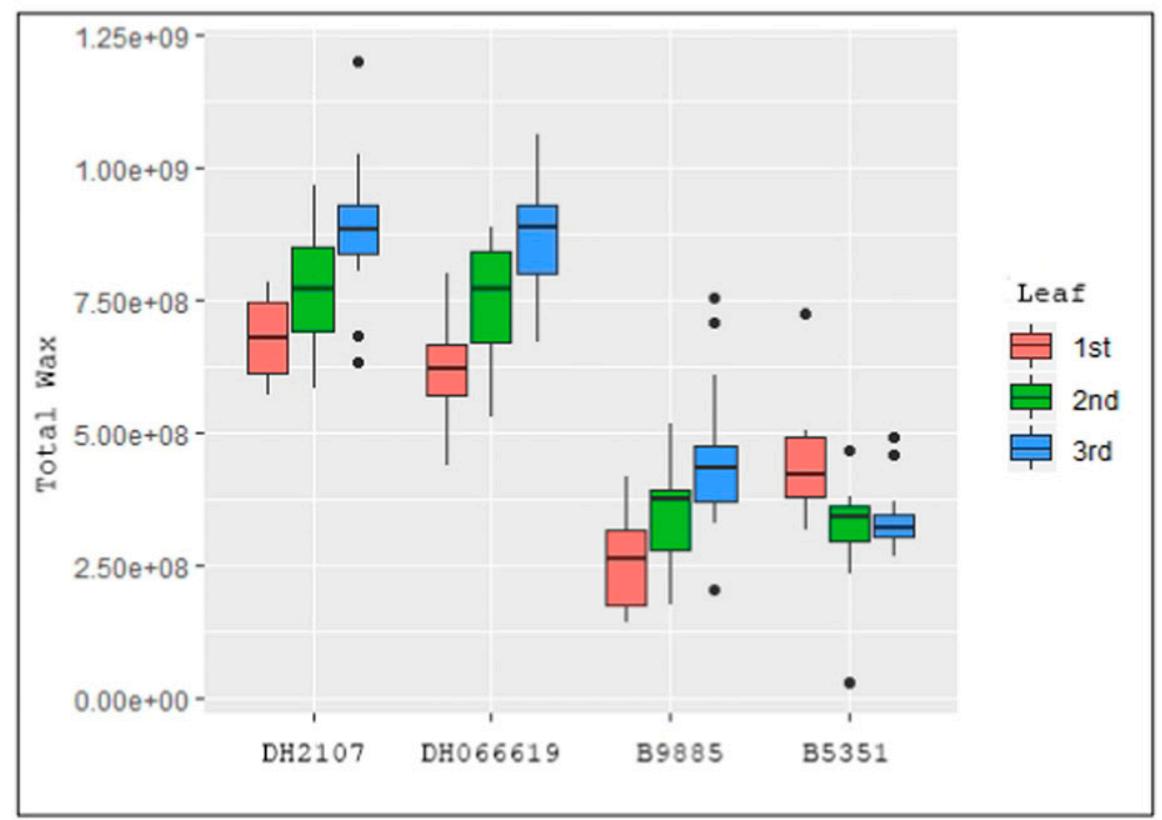

Fig. 1. Boxplots of amounts of hentriacontanone-16 (H16) (A) and total wax (B) adjusted to dry weight of the youngest (first), intermediate (second), and oldest (third) leaves sampled from plants of waxy doubled haploids (DH) 2107 and 066619, glossy B9885, and semiglossy B5351 lines of onion. obtained, stock solutions were prepared at 1 $\mathrm{mg} \cdot \mathrm{mL}^{-1}$, and $25-$ or $65-\mu \mathrm{L}$ volumes were run on the GCMS.

Individual peak areas were adjusted by the respective dry weights of the leaf pieces, and therefore represent peak area per gram leaf dry weight. Adjusted peak areas from the two pieces from the same leaf were averaged and used for all analyses. Coefficients of variation (Cv) for amounts of individual waxes were calculated (Excel; Microsoft, Redmond, WA). For statistical analyses of wax amounts from multiple leaves from multiple plants from the inbred lines, a split-plot analysis using R Studio (R Foundation for Statistical Computing, Vienna, Austria) considered sampling time as the main plot, and inbred lines and leaves as subplots.

\section{Results and Discussion}

Damon et al. (2014) reported that the most abundant waxes on leaves of the wild-type waxy onion are heptadecanol-1 (Heptol), hexacosanol-1 (Hex), octacosanol-1 (Oct1), triacontanol-1 (Tri), 1-ethenyloxy octadecane (Octd), 2-methyl octacosane (Met), heptacosane (Hept), and hentriacontanone16 (H16). However Damon et al. (2014) ran chemical standards on the GCMS only for the three most prominent waxes (H16, Oct1, and Tri), and identities of the other waxes were assigned based on probabilities from the mass spectrometer (similarity threshold > $80 \%$ ) and comparisons with leek (Allium ampeloprasum; Rhee et al. 1998). We ran chemical standards on the GCMS to confirm the identities of longer chain waxes on onion foliage. The peak initially identified by $\mathrm{Da}-$ mon et al. (2014) as Hex comigrated with its standard. Peaks initially reported as Met and Hept by Damon et al. (2014) comigrated with standards for the alkanes nonacosane (Non) and hentriacontane (Hent). The chemical standard for Hept migrated with a minor peak from waxy leaves that was not reported by Damon et al. (2014). These identities are consistent with the biosynthetic pathway for epicuticular waxes in plants. Synthesis of waxes begins with the production of longchain fatty acids with greater than 26 carbons (C), which enter the acyl reduction and decarbonylation pathways (Millar et al., 1999; Samuels et al., 2008). In the acyl reduction pathway, fatty acids with even

Table 2. Average percent (\%) amounts of epicuticular waxes on foliage of four inbred onion lines and \% coefficients of variation (cv) for these waxes on foliage of doubled haploid (DH) onions 2107 and 066619.

\begin{tabular}{|c|c|c|c|c|c|c|}
\hline \multirow[b]{2}{*}{ Wax } & \multicolumn{4}{|c|}{ Avg $\%$ of total wax on foliage of } & \multicolumn{2}{|c|}{$\mathrm{CV}$ for } \\
\hline & B9885 & B5351 & DH2107 & DH066619 & DH2107 & DH066619 \\
\hline Nonacosane & 2.5 & 4.7 & 1.8 & 1.5 & 31.6 & 35.1 \\
\hline Hexacosanol-1 & 4.6 & 1.2 & 2.0 & 2.5 & 23.9 & 22.4 \\
\hline Heptadecanol-1 & 8.1 & 13.4 & 8.1 & 8.1 & 16.8 & 16.1 \\
\hline Triacontanol-1 & 17.8 & 5.6 & 9.9 & 11.5 & 35.2 & 36.1 \\
\hline
\end{tabular}


numbers of carbons are the substrate to produce fatty alcohols, such as Hex (C26), Oct1 (C28), and Tri (C30). The decarbonylation pathway results in loss of one carbon from the fatty acids to produce alkanes and ketones with odd numbers of carbons, such as the alkanes Hept (C27), Non (C29), and Hent (C31), and the ketone H16 (C31). The waxes identified by Damon et al. (2014) as heptol (C17) and Octd (C20) are not direct products of these two pathways, and their amounts were not significantly different among plants and leaves of the inbred onions (Table 1).

We grew highly inbred or DH onions in a greenhouse over time to reduce genetic and environmental variation on wax amounts among plants within each line. Nine waxes (Heptol, Hex, Oct1, Tri, Octd, Hept, Non, Hent, and H16) were detected on the foliage of all four inbreds. As previously reported (Damon et al., 2014), amounts of total epicuticular wax and H16 were highest on foliage of the waxy onions (DHs 2107 and 066619) and lower on the semiglossy (B5351) and glossy (B9885) inbreds (Fig. 1; Table 2). We calculated cvs for individual waxes on leaves of the waxy DH onions, and we observed that the highest Cvs were associated with less abundant waxes (Table 2). This may have resulted from variation of wax amounts on leaves, errors during preparation of samples, and/or estimation of GC peak areas for relatively minor waxes. However, the fatty alcohols Oct1 and Tri are among the most prevalent waxes on the leaves of the waxy DHs 2107 and 066619 , representing $\approx 16 \%$ and $11 \%$ of total wax; and they showed relatively high cvs at $\approx 30 \%$ and $36 \%$, respectively. H16 is the most abundant wax on leaves of the waxy DHs, averaging $56 \%$ of total wax, and it showed the lowest $\mathrm{CV}$ at $\approx 18 \%$. Peak areas for docosane were expected to be the same because the same amount was added to each chloroform extraction; the average $\mathrm{CV}$ across all extractions was $6.6 \% \pm 2.3 \%$ and represents technical variation in preparation of samples or GC runs. The higher cVs observed for all waxes relative to the docosane control reveal unexplained variation among plants of highly inbred onions grown in a greenhouse, and these would likely be higher on field grown plants due to greater environmental variation.

We assessed variation for amounts of epicuticular waxes among leaves on the same plant and across differently aged plants from the four inbreds. Amounts of waxes measured on plants of three different ages (sampling times) were significantly $(P<0.05)$ different only for the alkane Hent (Table 1), indicating that multiple samplings from the same plant over time may not be necessary. Inbred lines had different leaf phenotypes and showed significant $(P<0.05)$ differences for amounts of fatty alcohols Hex, Oct1, and Tri; the alkane Hent; ketone H16; and total wax (Table 1). Older leaves on the same plant had significantly $(P<0.01)$ higher amounts of all waxes except Heptol and Octd (Table 1). The line $\times$ leaf interaction was significant $(P<0.05)$ for fatty alcohols Hex, Oct1, and Tri, the ketone H16, and total wax (Table 1), and this was due to lower wax on older leaves of semiglossy B5351 (Fig. 1). These results indicate that it may not be necessary to sample multiple leaves from the same plant to measure relative amounts of waxes.

Our results indicate that resources to measure epicuticular waxes may be best used to sample a larger number of onion plants in a population, as opposed to multiple samplings of leaves on the same plant over time (Table 1). The larger cvs associated with amounts of individual waxes (Table 2) will likely reduce response to selection to alter profiles. However, selection for less H16 and/ or greater amounts of other waxes with lower CVs, such as the alkane hent or fatty alcohol hex (Table 2), may respond better to selection to produce onion populations that suffer less feeding damage by onion thrips.

\section{Literature Cited}

Boateng, C.O., H.F. Schwartz, M.J. Havey, and K. Otto. 2014. Evaluation of onion germplasm for resistance to Iris yellow spot (Iris yellow spot virus) and onion thrips, Thrips tabaci. Southwest. Entomol. 39:237-260, doi: 10.3958/ 059.039.0218
Cramer, C.S., N. Singh, N. Kamal, and H.R. Pappu. 2014. Screening onion plant introduction accessions for tolerance to onion thrips and iris yellow spot. HortScience 49:1253-1261, doi: 10.21273/HORTSCI.49.10.1253.

Damon, S.J., R.L. Groves, and M.J. Havey. 2014 Variation for epicuticular waxes on onion foliage and impacts on numbers of onion thrips. J. Amer. Soc. Hort. Sci. 139:495-501, doi: 10.21273/JASHS.139.4.495.

Diaz-Montano, J., M. Fuchs, B.A. Nault, and A.M. Shelton. 2010. Evaluation of onion cultivars for resistance to onion thrips (Thysanoptera: Thripidae) and Iris yellow spot virus. J. Econ. Entomol. 103:925-937, doi: 10.1603/EC09263.

Hoagland, D.R. and D.I. Arnon. 1950. The waterculture method for growing plants without soil. Circ. 347. California Agr. Expt. Station, Berkeley, CA.

Hyde, P.T., E.D. Earle, and M.A. Mutschler. 2012. Doubled haploid onion (Allium cepa L.) lines and their impact on hybrid performance. HortScience 47:1690-1695, doi: 10.21273/HORTSCI.47.12.1690.

Jones, H.A., S.F. Bailey, and S.L. Emsweller. 1934. Thrips resistance in onion. Hilgardia 8:215232, doi: $10.3733 /$ hilg.v08n07p213.

Millar, A.A., S. Clemens, S. Zachgo, E.M. Giblin, D.C. Taylor, and L. Kunst. 1999. CUT1, an Arabidopsis gene required for cuticular wax biosynthesis and pollen fertility, encodes a very-long-chain fatty acid condensing enzyme. Plant Cell 11:825-838, doi: $10.1105 /$ tpc.11.5.825.

Molenaar, N.D. 1984. Genetics, thrips (Thrips tabaci L.) resistance and epicuticular wax characteristics of nonglossy and glossy onions ( $\mathrm{Al}$ lium cepa L.). $\mathrm{PhD}$ diss, University of Wisconsin-Madison.

Munaiz, E.D., R.L. Groves, and M.J. Havey. 2020. Epicuticular leaf waxes among onion accessions selected for reduced damage by onion thrips. J. Amer. Soc. Hort. Sci. 145:30-35, doi: 10.21273/JASHS04773-19.

Rhee, Y., A. Hlousek-Radojcic, P. Ponsamuel, D. Liu, and P. Beittenmiller. 1998. Epicuticular wax accumulation and fatty acid elongation activities are induced during leaf development of leeks. Plant Physiol. 116:901-911, doi: 10.1104/pp.116.3.901.

Samuels, L., L. Kunst, and R. Jetter. 2008. Sealing plant surfaces: Cuticular wax formation by epidermal cells. Annu. Rev. Plant Biol. 59:683-707, doi: 10.1146/ annurev.arplant.59.103006.093219. 